\title{
In vitro Comparison of Dimensional Stability of Stone Dies Obtained from Two Elastomers after Two Treatments
}

\author{
${ }^{1}$ Venkatesan Narayanan, ${ }^{2}$ Jayantha Padmanabhan \\ ${ }^{1}$ Associate Professor, Department of Prosthodontics, Adhiparasakthi Dental College, Melmaruvathur, Tamil Nadu, India \\ ${ }^{2}$ Principal and Head, Department of Periodontics, Adhiparasakthi Dental College, Melmaruvathur, Tamil Nadu, India
}

Correspondence: Venkatesan Narayanan, Associate Professor, Department of Prosthodontics, Adhiparasakthi Dental College Melmaruvathur, Tamil Nadu, India, e-mail: naravenky@yahoo.com

\section{ABSTRACT}

Aim: The aim of the study was to compare the dimensional stability of dies obtained from addition silicone and polyether impressions that were reheated or subjected to vacuum treatment.

Materials and methods: A master die was constructed of a rectangular stainless steel block on to which a photosensitive nylon printing plate attached which contains engraved test grooves. A custom-tray was fabricated and impressions were made using addition silicone and polyether before and after the two treatments. A total of 90 impressions and dies were made from both the elastomers and divided as control group, group I (reheated impressions) and group II (vacuum-treated impressions). A comparative analysis was done to determine which dies yielded the best dimensional accuracy compared to that of the master die.

Results: The minimum percentage dimensional change was observed in test dies made from addition silicone impressions of group I (reheated impressions), followed by the test dies made from polyether impressions in control group. The maximum percentage dimensional change was observed in test dies made from polyether impressions in group I (reheated impressions), followed by the test dies made from addition silicone impressions in group II (vacuum-treated impressions).

Conclusion: The dies obtained from reheated addition silicone impressions yielded the best dimensional stability overall when compared with that of the master die. The dies made of polyether impressions after reheating were not clinically acceptable, because of its hydrophilic nature swelled when they were reheated in a water bath

Keywords: Dental die, Reheated impressions, Vacuum-treated impressions, Master die, Test dies.

\section{INTRODUCTION}

A dental die is intended to be an exact replica of a tooth so that the restorations made on it are as accurately fitting as possible. A working cast-and-die system must provide surface detail, dimensional accuracy, strength and resistance to abrasion. W ith the present laboratory practice of placing a die spacer on the replicated, prepared tooth surfaces of stone dies that allow space for the luting agent, the necessity of accurate surface reproduction may not appear to be as important. ${ }^{1}$ Type IV dental stone, are composed of cuboidal shaped particles of á hemihydrate with reduced surface area, which provide the required properties of strength, hardness and minimal setting expansion. Therefore, the dimensional stability of the dies is a prime requisite to a serviceable, well-adapted cast restoration.

The first step in the search for an accurate die is a perfect impression material. There are numerous impression materials available ranging from al ginate to the elastomers. The elastomers now have overshadowed every other impression materials with their superior properties. A mong the elastomers, the addition silicone and polyether exhibited superior properties over others. Owing the credit to various researchers, the addition silicone and polyether with their excellent surface quality reproduction, best dimensional stability and low shrinkage, strongly influenced the selection of these materials in this study.

The disadvantages of addition silicones are poor wettability, entrapment of air in critical areas, such as preparation margins or pin-holes that often occur when silicone impressions are poured. Clinical experience has shown that voids may occur in casts as a result of the production and release of free hydrogen during polymerization. These voids may be large or numerous enough to produce a surface roughness that can affect the fit of the resulting fixed prosthesis. ${ }^{2}$ To minimize this problem, several treatments with varying levels of success have been proposed, (a) conditioning the impression surfaces with surface active substances, ${ }^{3}$ (b) adding surfactants to the impression $\mathrm{mix}^{3}$ (c) radiofrequency glow discharge or plasma treatment to the impression surfaces, ${ }^{4}$ (d) application of vacuum and pressure to the impressions before pouring the casts, ${ }^{2}$ (e) reheating the impressions before pouring the casts. The extent that these treatments on the dimensional stability of the dental dies that are used to make precise cast restorations is unknown. Therefore, the objective of this study was to evaluate and compare the dimensional stability of type IV gypsum dies made from addition silicone and polyether impression materials subjected to vacuum or reheat treatment. 


\section{MATERIALS AND METHODS}

The methods for analyzing the dimensional stability of dies obtained from two elastomeric impression materials that were subjected to vacuum and reheat treatment were divided into the following phases:

1. Preparation of the master die.

2. Preparation of the test dies for control group, after reheating to $37^{\circ} \mathrm{C}$ for 30 minutes (group I), and after subjecting the impressions to $28 \mathrm{psi}$ vacuum (group II).

3. Estimation of the dimensional stability of the test dies made from control group, groups I and II.

4. Comparison of the dimensional stability of the test dies made from control group, groups I and II.

\section{Preparation of the Master Die}

The stainless steel apparatus in the shape of the lower edentulous model was made (Fig. 1). It consists of the master die made of a rectangular stainless steel block of $6 \times 6 \times 38 \mathrm{~mm}$ on to which test grooves of varying thickness ranging from 235 to $255 \mu \mathrm{m}$ was engraved in a photosensitive nylon printing plate (Printight - J Type, Toyobo Co. L td, Osaka) attached on it (Figs 2 to 4 ).

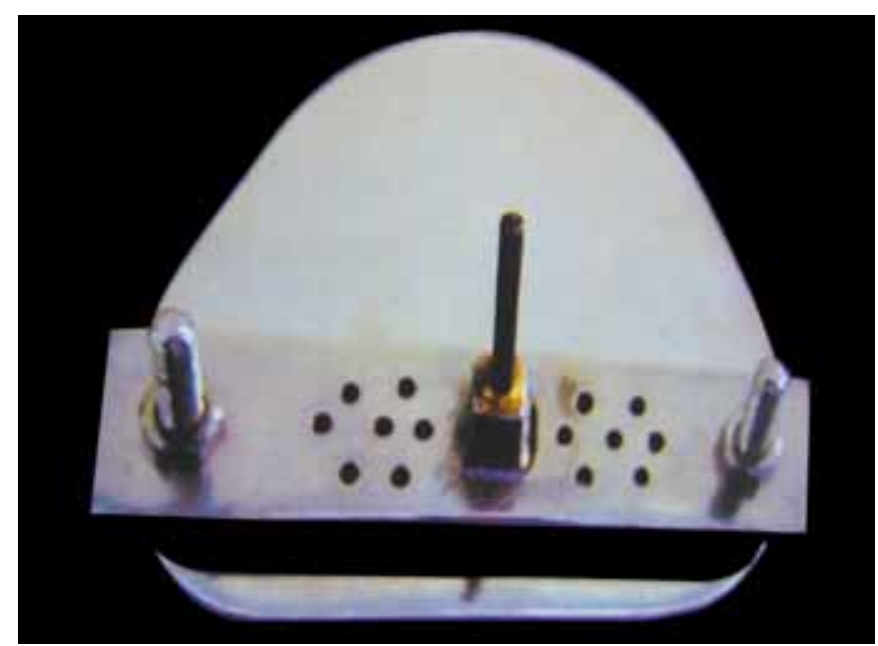

Fig. 1: Test apparatus with custom tray

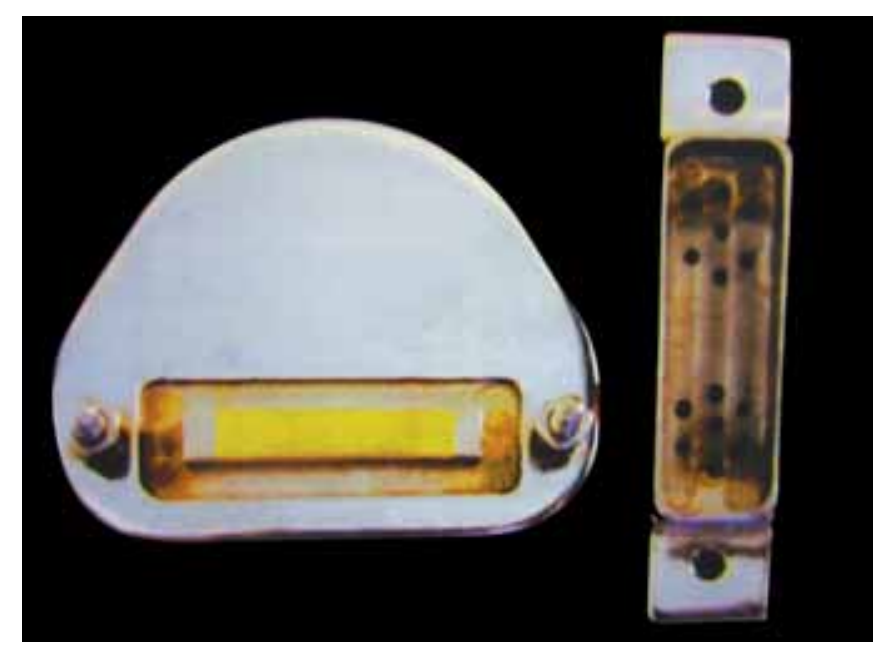

Fig. 2: Apparatus with custom tray and master die

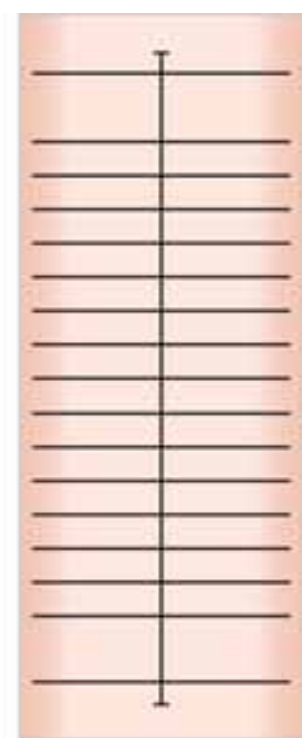

Fig. 3: The master die used for the study

The master die had two points namely, point A and B. For assessing the dimensional stability, the distance between point $A$ and $B$ (dimension D) was used (Figs 2 to 4 ).

A custom-tray was fabricated of $0.75 \mathrm{~mm}$ thick stainless steel plate. The distance between the inside of the tray along the sides of the master die was $4 \mathrm{~mm}$ and to the top of the master die was $2 \mathrm{~mm}$ (Figs 2 to 4).

A carbide bur shaft was attached to the top of the custom tray serving as a handle and to align it in the vertical arm of the dental surveyor while the impressions were made. This was done to standardize the position of the custom tray to the master die (Fig. 5).

\section{Preparation of the Test Dies for Control Group, Groups I and II}

B efore making the impressions, the apparatus with the master die was mounted on a survey table of a dental surveyor stored at $32^{\circ} \mathrm{C}$ as per the A merican Dental A ssociation Specification No. $19 .{ }^{5}$ Prior to each use, surface debris was removed from

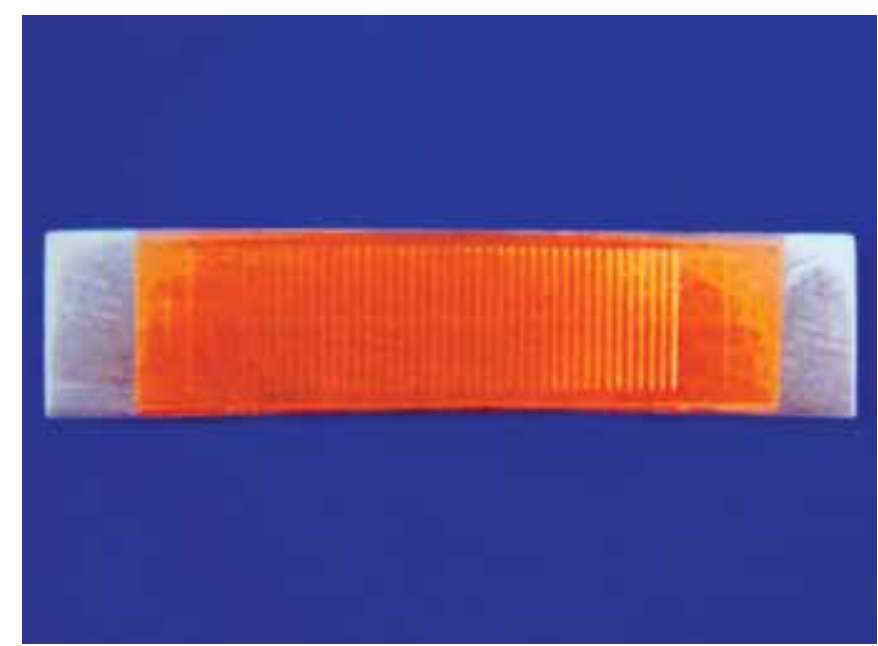

Fig. 4: Master die 
In vitro Comparison of Dimensional Stability of Stone Dies Obtained from Two Elastomers after Two Treatments

\begin{tabular}{llllll}
\hline \multicolumn{5}{c}{ Table 1: Elastomeric impression materials and die stone used in this study } \\
\hline Type & Product & Manufacturer & Technique & Consistency & Batch no. \\
\hline A ddition silicone & A quasil monophase & Densply/Caulk, M ilford, De & Single mix & M edium & 60578100 \\
Polyether & Impregum-F & 3M ESPE, Germany & Single mix & M edium & 31713 \\
Type IV die stone & Ultrarock & Kalabhai Karson Ltd, M umbai & & & 241112 \\
\hline
\end{tabular}

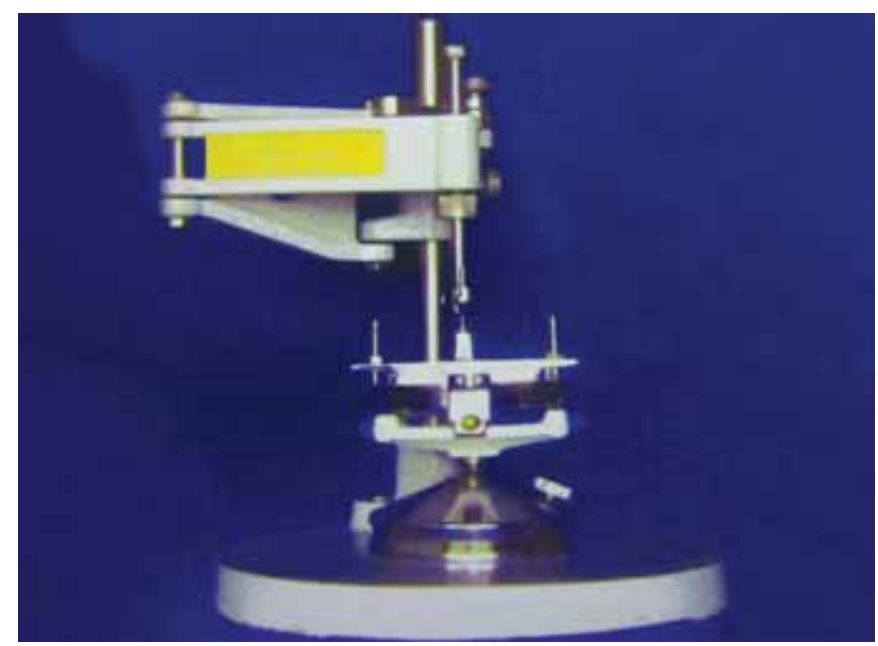

Fig. 5: Test apparatus in dental surveyor

the master die with methyl alcohol on a cotton gauze sponge. All the impressions were made using monophase technique after application of the universal tray adhesive (Batch no: 170381, Kulzer, Germany).

A total of 90 impressions and dies were made and is to be analyzed were divided as follows:

- For control group, 15 impressions from addition silicone and 15 impressions from polyether were made and dies were poured in the atmospheric pressure served as the control (Fig. 9 and Table 1). The impression materials were mixed at room temperature, loaded in the tray aligned in the dental surveyor and the impressions were made. The assembly was immediately transferred to the water bath at $37^{\circ} \mathrm{C}$ for 15 minutes to simulate the oral conditions. The impressions were immersed in $2 \%$ acid gluteraldehyde (B atch no: 46080, SD Fine-Chem LTD, M umbai) for 30 minutes, rinsed for 45 seconds in potable water, dried by gentle air stream for 10 seconds, and permitted to bench set for 30 minutes before the dies were poured. A precision weighing machine was used to measure the appropriate die stone (Fig. 10). All dies were poured with the recommended water/powder ratio $(22 \mathrm{cc} / 100 \mathrm{gm})$, hand spatulated and mixed in vacuum (Easy-mix, Bego, Germany) for 15 seconds (Fig. 11).

- For group I, the impressions were made as described for control group and disinfected. The impressions were cooled down to room temperature for 10 minutes. A fter cooling, the impressions were reheated to $37^{\circ} \mathrm{C}$ for 30 minutes by placing the impressions in the staining bath which was kept immersed in water bath (Forma scientific, Germany) and the dies were poured (Fig. 6).

- For group II, the impressions were made as described for control group and disinfected. Theimpressions were cooled down to room temperature for 10 minutes. A custom-made cylindrical chamber with vacuum gauge in pounds/sq. inch is connected to the air inlet (muffler) of the dental compressor to create 28 psi vacuum (Figs 7 and 8). The vacuum chamber has a nonreturn valve (NRV) to maintain the vacuum that was created inside the chamber for any specific time and a release valve to release the vacuum. The impressions were then subjected to 28 pounds/square inch vacuum for 5 minutes before pouring the dies.

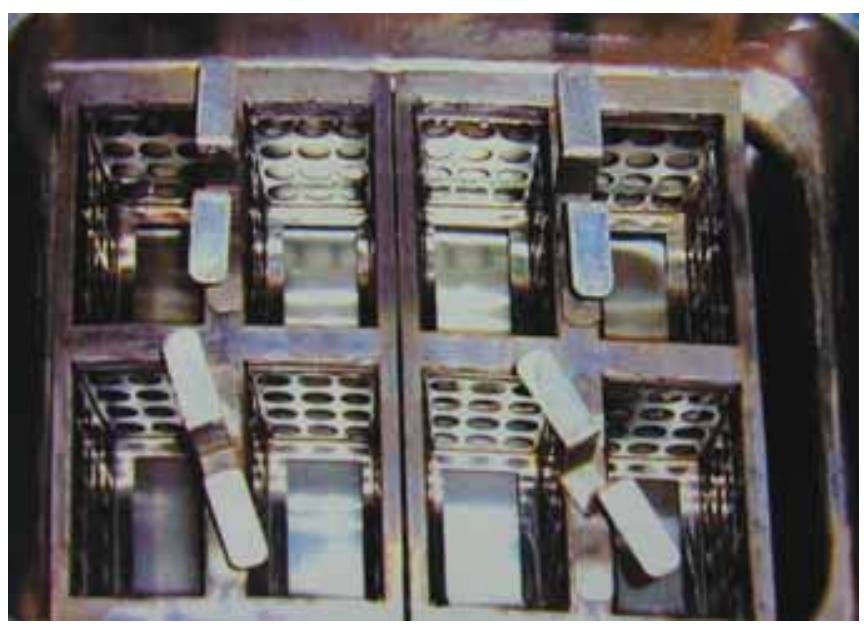

Fig. 6: Water bath for reheating the impressions

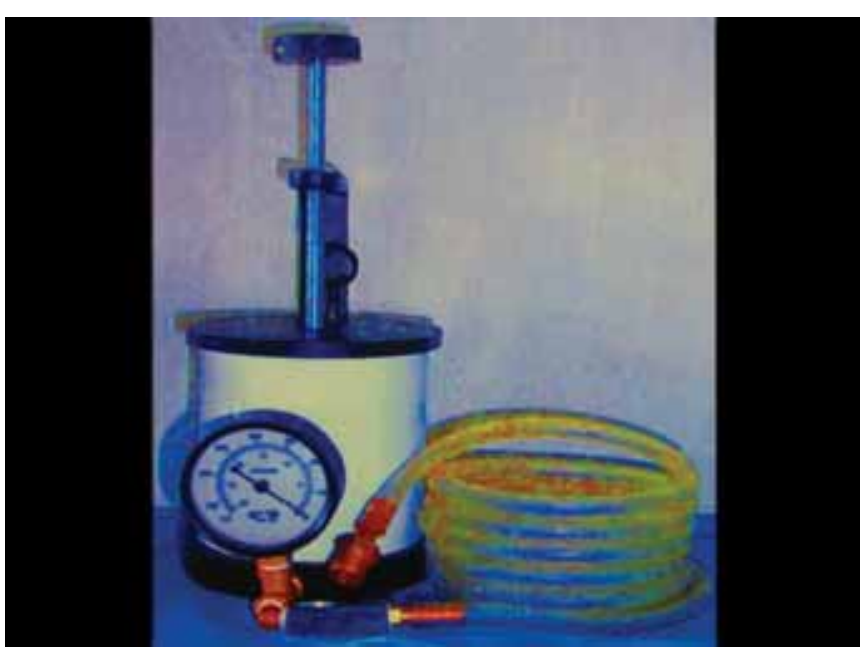

Fig. 7: Custom-made vacuum chamber used for the study 


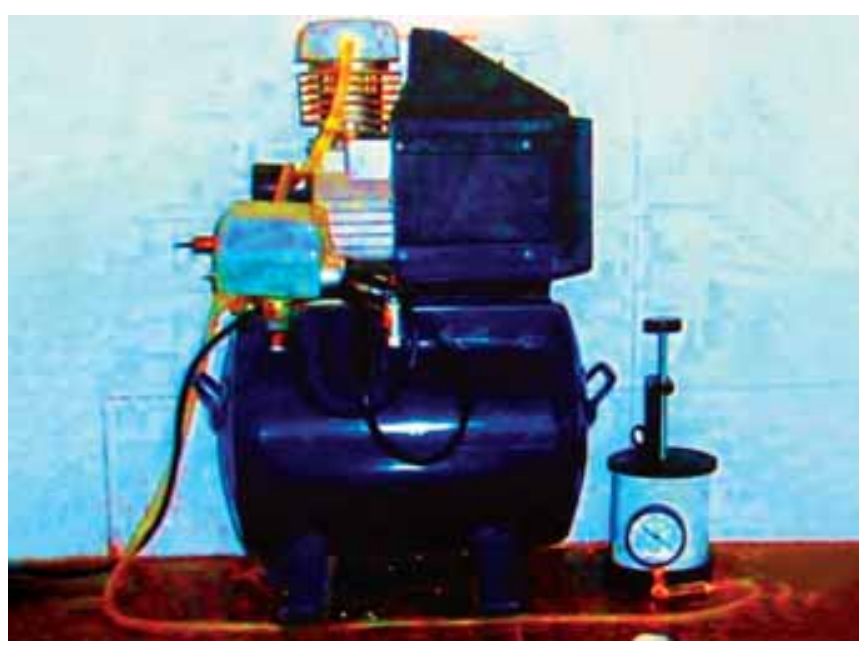

Fig. 8: Vacuum chamber attached to the dental compressor

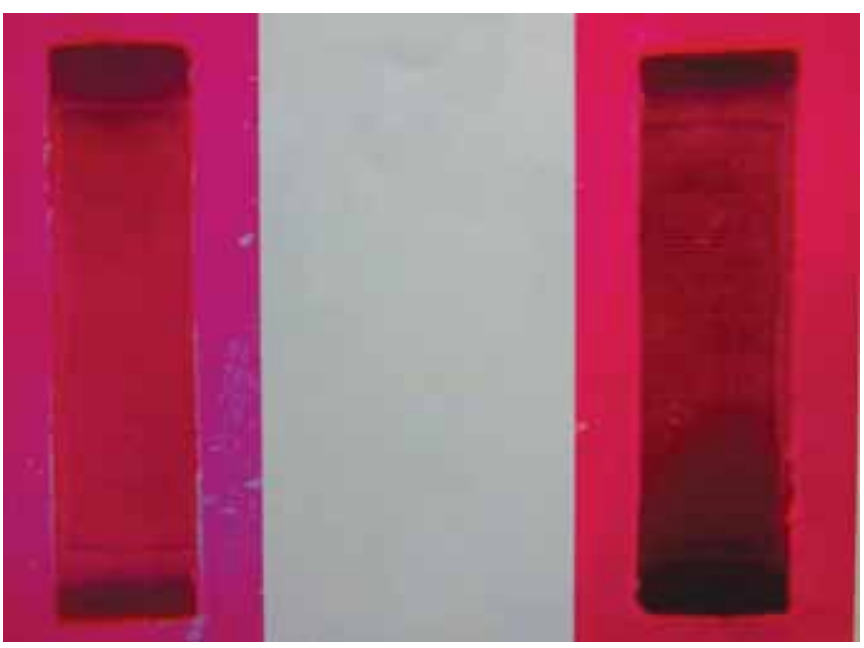

Fig. 9: Impressions of the master die

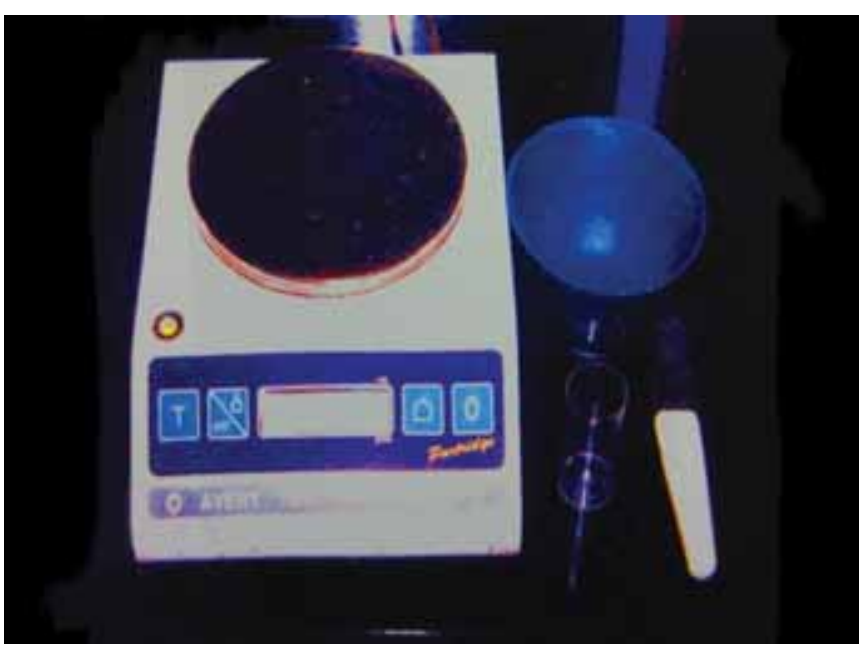

Fig. 10: Precision weighing machine to measure die stone

\section{Estimation of the Dimensional Stability of the Test Dies for Control Group, Groups I and II}

- To measure the dimensional stability, a measuring microscope (Optic traveling microscope, Suswax, India) capable of measuring up to $1 \mu \mathrm{m}$ was used to measure the distance between the points $A$ and $B$ (dimension $D$ ) on the

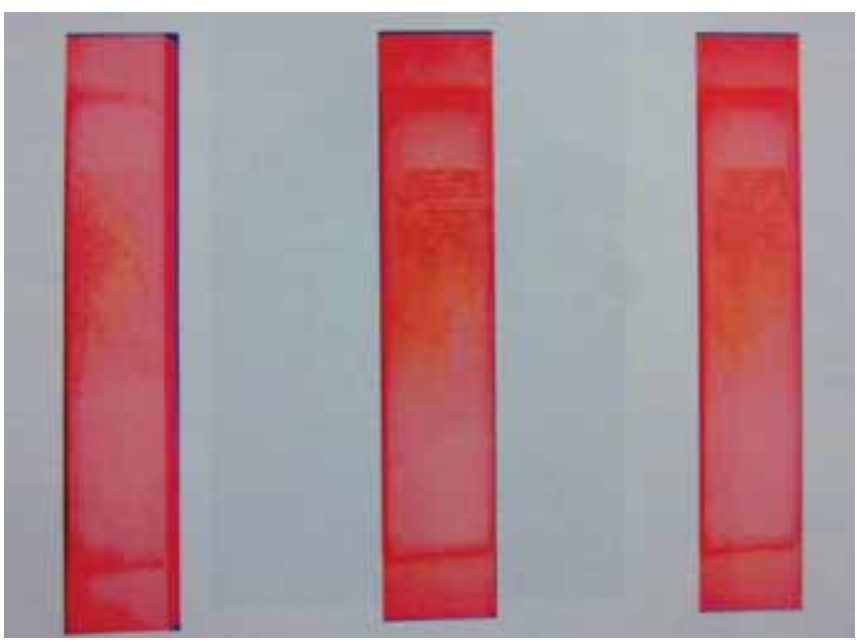

Fig. 11: Sample dies

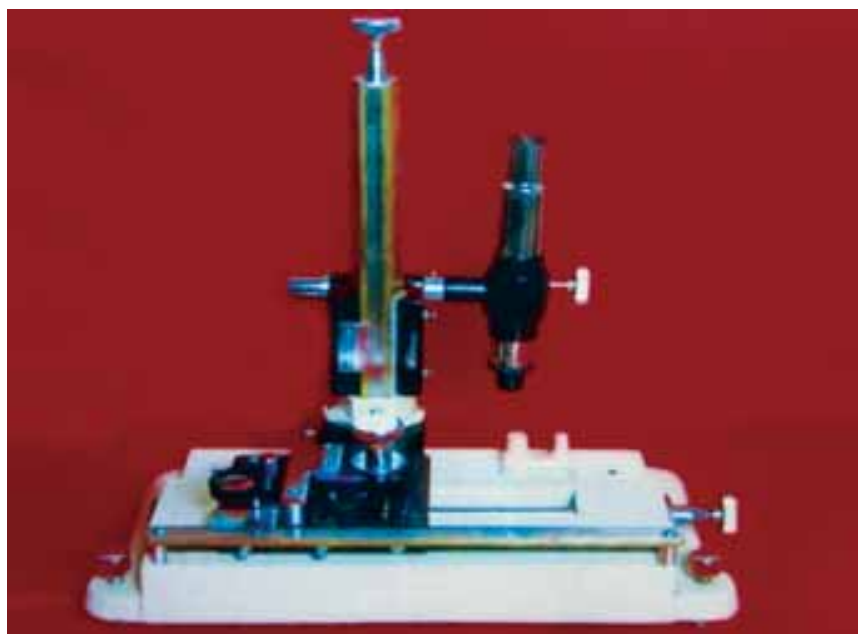

Fig. 12: Traveling microscope used in the study

test dies (Fig. 12). Each dimension was measured three times for each test die and the mean of the three readings was used.

- In this study, the direct measurement of the stone dies using a high resolution traveling microscope between the sharp margins of the die, between the two lines recommended by the ADA specification no. 19 was used. ${ }^{5}$

- The dimensional changes are expressed in micrometers and as percentage change from the dimensions of the master die. The I $\mathrm{S} 0$ specification number 4823 recommends that the results of the dimensional changes should be reported as follows: ${ }^{6}$

Percent dimensional change $=$

Dimension of the sample - Dimension of the master die Dimension of the master die

\section{Comparison of the Dimensional Stability of all the} Test Dies Obtained from Polyether and Addition Silicone Impression Materials

The comparison of each individual groups was analyzed with the master die for the dimensional stability under the following categories: 
In vitro Comparison of Dimensional Stability of Stone Dies Obtained from Two Elastomers after Two Treatments

1. Comparison of dimensional stability of test dies in control group with the master die.

2. Comparison of dimensional stability of test dies in group I with the master die.

3. Comparison of dimensional stability of test dies in group II with the master die.

\section{RESULTS}

The measurement of the master die for the study was obtained by the mean of four measurements from point $A$ to $B$ (dimension D) was $24.958 \mathrm{~mm}$. To compare the linear dimensional change of the test dies with that of the master die the analysis of variance (ANOVA) was used.

- In control group, the mean value for dimension $D$ in test dies made from addition silicone impressions was $24.92840 \mathrm{~mm}$ and $24.96480 \mathrm{~mm}$ for polyether impressions.

- In group I, the mean value for dimension D in test dies made from addition silicone impressions was $24.95193 \mathrm{~mm}$ and $24.71060 \mathrm{~mm}$ for polyether impressions.

- In group II, the mean value for dimension $D$ in test dies made from addition silicone impressions was $24.89167 \mathrm{~mm}$ and $25.02327 \mathrm{~mm}$ for polyether impressions.

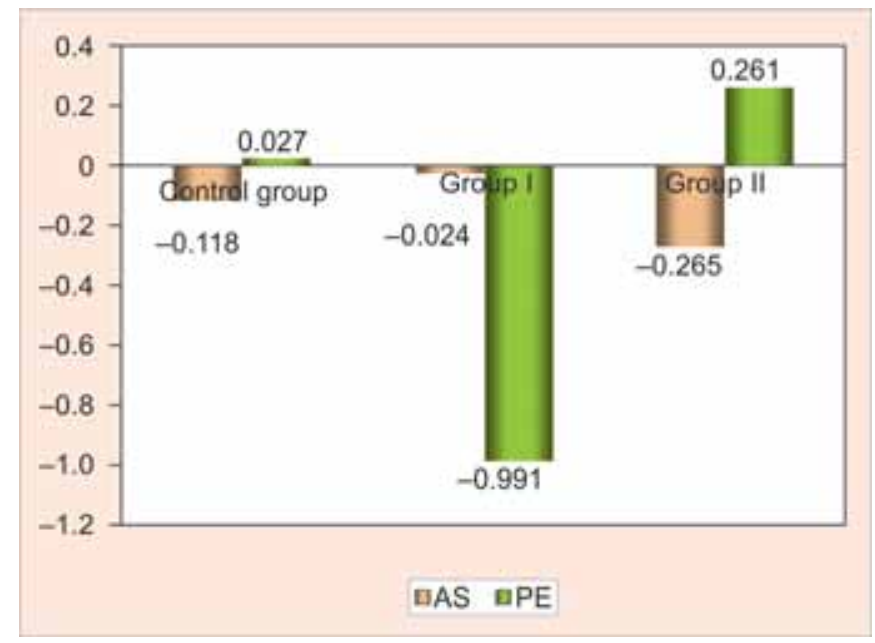

Fig. 13: Percentage relative dimensional change in control group, groups I and II

\section{CLINICAL SIGNIFICANCE}

If the percentage relative dimensional change in test dies made from either addition silicone or polyether impressions were less than $0.5 \%$, it is considered clinically acceptable (Fig. 13). ${ }^{5}$ A clinically unacceptable dies could lead to a clinically unacceptable castings that would not seat on the prepared tooth or teeth unless compensatory laboratory techniques are initiated. Based on this, the results can be formulated as follows:

- The test dies made from addition silicone impressions in control group, groups I and II were smaller $(-0.024$ to $-0.265 \%$ ) indicating shrinkage of the impression material. The clinical significance of this amount of shrinkage is negligible. Therefore all the test dies made from addition silicone impressions in control group, groups I and II are clinically acceptable.
- The test dies made from polyether impressions in control group and group II were larger ranging from +0.027 to $+0.261 \%$ indicating expansion of the impression material. The clinical significance of this amount of shrinkage is negligible. Therefore, these test dies are clinically acceptable. $0 \mathrm{n}$ the other hand, the dies that were made with polyether impressions in group I were smaller $(-0.991 \%)$ when compared to the master die. This indicated that the polyether impression material, because of its hydrophilic nature, had swollen when it was reheated at $37^{\circ} \mathrm{C}$ for 30 minutes in a water bath. Therefore the resulting test dies were significantly smaller when compared to the master die and were not clinically acceptable.

\section{DISCUSSION}

- The test dies made from addition silicone impressions that were subjected to reheat treatment foll owed by the polyether impressions in control group exhibited the overall best dimensional stability when compared with that of the master die.

- The test dies made from addition silicone impressions in control group and subjected to vacuum were also clinically acceptable according to A DA specification.

- The test dies made from polyether impressions when subjected to vacuum treatment also were clinincally acceptable according to A DA specification but the test dies made from polyether impressions that were subjected to reheat treatment resulted in dies that were not clinically acceptable.

- Therefore, in this study, we conclude that both the addition silicone and polyether impression materials provided dimensionally stable dies without being subjected to any treatments with polyether being superior over addition silicones. B ut the addition silicones yielded the overall best dimensionally stable dies when it was subjected to reheat treatment.

\section{REFERENCES}

1. D rennon DG, J ohnson $G H$. The effect of immersion disinfection of elastomeric impressions on the surface detail reproduction of improved gypsum casts. J Prosthet Dent 1990; 63;233-41.

2. M orford HT, Tames RR, Zardiackas LD. Effects of vacuum and pressure on accuracy, reproducibility, and surface finish of stone casts made from polyvinyl siloxane. J Prosthet Dent 1986;55;466-71.

3. Robinson BP, Dunne SM, Millar BJ. An in vitro study of a surface wetting agent for addition reaction silicone impressions. J Prosthet Dent 1994;71;390-93.

4. Nikolaos V assilakos, Claudio Pinheiro, K rister Nilner. Effect of plasma treatment on the w ettability of elastomeric impression materials. J Prosthet Dent 1993;70:165-71.

5. Reports of councils and bureaus: Revised A merican Dental A ssociation Specification N 0. 19 for N on-A queous, Elastomeric Dental Impression M aterials. J Am Dent A ssoc 1977;94:733.

6. Chaffee NR, Bailey JH. Sherrard: Dimensional accuracy of improved dental stone and epoxy resin die materials. Part I. J Prosthet Dent 1997;77:131. 